\title{
Restrictive Materialism and the Propositional Attitudes
}

\author{
Bennett Holman
}

Received: 10 August 2010 / Accepted: 15 August 2010 /

Published online: 21 September 2010

(C) The Author(s) 2010. This article is published with open access at Springerlink.com

\begin{abstract}
It has been argued that naturalizing the mind will result in the elimination of the ontology of folk psychology (e.g. beliefs and desires). This paper draws from a wide range of empirical literature, including from developmental and cross-cultural psychology, in building an argument for a position dubbed "restrictive materialism". The position holds that while the ontology of folk psychology is overextended, there is a restricted domain in which the application of the folk ontology remains secure. From the evidence of developmental uniformity and cross-cultural ubiquity of beliefs and desires, it is argued that the ontology (but not the principles) of folk psychology may be incorrigible. Thus, even if radically false as a description of first-order brain processes, beliefs and desires might be an unavoidable second-order brain process. Given that the domain of psychology is how humans think, if the above argument is correct, then beliefs and desires will continue to earn their rightful place in the ontology of any future psychology, in just the same way as any other scientific entity.
\end{abstract}

Keywords Propositional attitudes $\cdot$ Folk psychology $\cdot$ Restrictive materialism $\cdot$ Beliefdesire explanation

\section{Introduction}

Eliminative materialism is the thesis that our commonsense conception of psychological phenomena constitutes a radically false theory, a theory so fundamentally defective that both the principles and the ontology of that theory will eventually be displaced, rather than smoothly reduced, by completed neuroscience. (Churchland 1981, p.67)

It has been argued that naturalizing the mind entails eliminating our commonsense ontology. While the claim that our current ontology of mental states is radically false is

B. Holman $(\bowtie)$

Department of Logic and Philosophy of Science, University of California Irvine, Irvine, CA 92697, USA

e-mail: bholman@uci.edu 
counterintuitive, if our understanding of mental states is radically false, what good are our intuitions? The prospect of being massively in error is unsettling. Yet it may be the case that any position invoking belief, desires, or propositional attitudes more generally, is as Churchland claims: nothing but modern day alchemy. If so, 'belief' and 'desire' will one day take their place alongside 'caloric fluid' and 'phlogiston' as arcane posits of an outdated theory. While Churchland argues that the intentional paradigm is completely bankrupt, I will argue that it is merely overextended. Indeed, when the intentional paradigm is tasked with the explanation of all human psychology, failures abound. However, failure in some domains does not entail the nonexistence of a restricted domain within which it will succeed. I will attempt to specify where the intentional paradigm succeeds and why I think it will escape elimination, viz. I will defend a position one might call restrictive materialism.

Primarily, I will assess the prospects for propositional attitudes in a naturalized ontology of the mind. If our folk ontology were radically false, large parts of clinical, social, and developmental psychology would be futile. I will argue that the the intentional paradigm which undergirds these disciplines remains secure. I will review evidence that contradicts Churchland's speculative developmental psychology and that casts doubt on the corrigible (if not theoretical) nature of folk psychology. Finally, I elaborate the implications of restrictive materialism for psychology and philosophy of mind.

\section{The Prophecy}

Such an examination will make little sense, however, unless it is first appreciated that the relevant network of commonsense concepts does indeed constitute an empirical theory, with all the functions, virtues, and perils entailed by that status. (Churchland 1981, p.69)

The case for eliminative materialism (EM) rests on the theoretical nature of folk psychology (FP). I will contend that while there are theory-like aspects of FP, the way in which FP is acquired in childhood is disanalogous. Given that Churchland is wrong about how children acquire FP, it is not ipso facto the case that his argument for EM is fatally flawed. However, cross-cultural research on the development of a theory of mind (ToM) suggests the basic ontology of FP is fixed in ways that make EM unlikely.

The prophesy of EM is that propositional attitudes are a hopeless ontology that will eventually be looked upon as the fumblings of humans' first, prescientific, attempts at selfunderstanding. Churchland's general argument for EM proceeds essentially as follows:

(1) FP is a theory.

(2) As a theory of human behavior, FP is radically flawed.

(3) The principles and ontology of radically flawed theories are eventually eliminated.

Thus:

(4) The principles and ontology of FP will be eliminated.

I will argue that the first premise is false by noting several dissimilarities between FP and scientific theories. Because I admit that folk psychology is theory-like, it is not inherently a problem for my view if there are similarities between FP and 
scientific theories. Only the similarities that bear on whether FP will be eliminated are pertinent here.

Though not articulated in the synopsis above, Churchland's argument rests on another premise: FP is corrigible. Indeed, Churchland (1991) notes this explicitly (p. 38) and elaborates the position in earlier works:

What needs to be appreciated here is that an infant has a great need to generate or acquire a conceptual framework with which to comprehend the states and activities of the world at large. The nascent mind must learn the parameters of its own being, no less than the parameters of the universe that contains it. With time it does learn about itself, but by a process of conceptual development that differs none from the process by which it maps the external world. (Churchland 1979, p.99, italics added)

Churchland claims that the process by which we come to know ourselves and others is merely a special case of a more general ability to learn from a pervasive social environment (Churchland 1979, p.117). Thus, if learning a ToM is dependent on the same principles that allow children to learn theories in general, we would not expect a selective impairment of a ToM. Nor would we expect to find children with significantly impaired IQ's but a preserved ToM, just as no one expects there to be people with a preserved ability to learn Newtonian mechanics. Yet this is precisely what we find with the ToM. ${ }^{1}$

Standard experiments in the ToM literature focus on the ability to recognize that another person may hold beliefs not shared by the subject. For example, a typical false belief task involves displaying a box of candies filled with pencils and asking the subject what a naïve observer will think is in box. Young children consistently say 'pencils', while older children are able to bracket off what they believe and attribute the false belief 'candies' to a naïve observer.

A vast body of evidence shows children and adolescents with autism have profound deficits in ToM tasks (Baron-Cohen et al. 1985; Baron-Cohen 1991, 1995; Happe 1995; Perner et al. 1989). Furthermore, such deficits are specific to the mental domain. (Baron-Cohen et al. 1986; Zalla et al. 2006). For example, in one false belief task, an observer witnesses an object placed in a cupboard and then leaves the room. In their absence the object is moved to a trunk. The child is asked where the observer will look for the object when they return to the room. In the structurally isomorphic task an object is placed in a cupboard and a polaroid is taken. While the picture is developing the object is moved to the trunk. The child is asked what the picture will show when it develops. Normally developing children typically find the false belief task to be at least as easy as the false photograph test. Children with autism fail the false belief test, but not the false photograph test (Leekam and Perner 1991). ${ }^{2}$ Thus, the deficit is not merely the ability to understand meta-representations

\footnotetext{
${ }^{1}$ For a summary of the foundational literature as it relates to autism, see Baron-Cohen et al. (2000); for a more general review see Doherty (2008).

${ }^{2}$ This result has been replicated and demonstrated in other tasks such as maps in which the location of an object is marked on the map and then subsequently the location of the object is changed. Children with autism outperform unimpaired children (matched for IQ) on the false map task, while performing at chance levels in the false belief task (viz. they realize that the map will still depict the old location if it is not updated, but do not realize that the person will continue to believe the object is in the old location when they do not witness the switch (Leslie and Thaiss 1992)).
} 
or decouple representations of the world at present from a past state of affairs. As noted by Zahavi and Parnas (2003) what seems to be lacking is not the ability to generate theories, but an automatic and effortless ability to parse social interaction.

The second half of the double-dissociation is the selective sparing of a ToM despite pervasive impairment in other areas of mental functioning. This half is exhibited by people with Williams syndrome (WS), a rare genetic disorder that involves a spared ability to understand other minds (Tager-Flusberg et al. 1998). Nearly all WS subjects passed first-order false belief tasks (i.e. the misleading container task), while nearly a third were able to pass a second-order false belief task. $^{3}$ While there are further elaborations to this story, what is pertinent here is that, in contrast to Churchland's conception of ToM as reliant on general learning mechanisms, the double-dissociation illustrated above suggests a domain-specific ability.

At this point, an eliminativist could amend her argument in order to accommodate the evidence reviewed above. Further, addressing the challenge posed by the modified version goes a long way to deciding between EM and the position I will ultimately offer. The rejoinder goes something like this. The argument for EM doesn't hinge on the way that FP is learned. The fact that deaf children don't acquire a ToM (when their hearing parents don't use signing to discuss beliefs and desires (Vaccari and Marschark 1997)), shows that children without neurological impairment won't learn the theory on their own (Peterson and Siegal 2000). The fact that most children develop a ToM reflects the fact that most children grow up in a culture steeped in FP. All that is necessary for EM to hold is that FP is learned, corrigible, and radically false.

Granted that FP is learned, I will examine whether it is corrigible. First, consider the examples of false ontologies provided by Churchland. Notice that while terms like phlogiston, aether, and crystalline spheres were used and replicated in some communities, their use was limited to the influence of the communities that introduced them. If the FP westerners are familiar with is radically false, learned, and corrigible, then we should expect significant variation in the ontological posits of diverse cultures. Accordingly, in defense of his realist position, Fodor (1987) emphatically insisted, "There is, so far as I know, no human group that doesn't explain behavior by imputing beliefs and desires to the behavior. (And if an anthropologist claimed to have found such a group, I wouldn't believe him)" (p.132). I think this stubbornness is wrongheaded. For the eliminativist, finding out that all cultures advert to propositional attitudes would be just as surprising as finding that every culture adverts to the four humors theory of the human body. Furthermore, an easy course to show that it is possible to eliminate FP is to exhibit a culture that uses a radically different ontology to capture the mind.

Alternatively, if FP is innate and incorrigible, then all cultures will include beliefs and desires in their ontological framework. I propose that if cross-cultural research on FP reveals a uniformity, despite a variety of environmental conditions, though we

\footnotetext{
${ }^{3}$ In a second-order false belief task every actor in the story has true beliefs about the state of world, but one actor has a false belief about what a second actor believes about the world. Such a task requires the subject to keep track of what each actor believes about the world and what each actor believes about the beliefs of the other actors. People with high-functioning autism uniformly fail on such tasks (KarmiloffSmith et al. 1995).
} 
can not conclusively state that FP is innate and incorrigible, such uniformity counts as significant evidence for that position. In evaluating the universality of FP, I will consider two questions. First, is there overlap in the ontological posits of culturally diverse FPs, viz. do all cultures advert to beliefs, desires, etc.? Second, do diverse cultures share the same FP principles, viz. do all cultures advert to the same regularities in explaining and predicting behavior?

The answer to the first question is provided by an insightful systematic review of folk psychologies (Lillard 1998). The clearest finding is that the ontology of FP is not universal. There are entities thought to influence behavior in other cultures that do not appear in western FP. Describing the Lohorung of Nepal, Hardman (1981) notes, "mental and physical states of individual members are understood primarily in terms of forces outside the individual, such as spirits of the dead, ancestors, primeval beings or the natural world associated with them" (p.162). Yet, despite local variation, there does seem to be a core FP which is universal. To wit, the Lohorung do refer to beliefs and desires, they are just not thought to be the primary cause of behavior.

Further evidence concerning the ubiquity of beliefs and desires arises from crosscultural work on false belief tasks. Experiments have shown that children in the Baka (a group of hunter-gatherers) have similar developmental trajectories in acquiring a ToM (Avis and Harris 1991). This finding was subsequently replicated with other non-western children (Vinden 1999; Callaghan et al. 2005). Indeed, one should note that the very ability to perform such experiments rests on the fact that words like belief and desire can be meaningfully translated. Wierzbicka (1992) claims that terms akin to think, want, and feel are common to all languages. Though it is possible that there may be a culture with a radically different ontology, or subtle differences in ways that cultures construe the shared ontological commitments, this evidence suggests that a universal core exists.

The ubiquity of this ontological core is contrasted with a considerable amount of variation in the principles that people make use of in predicting behavior. Our common sense notions of explaining or predicting behavior by reference to internal mental states is far from universal. ${ }^{4}$ Hindus tend to attribute behaviors to the situations that people find themselves in (Miller 1984), the Cheyenne explain behavior in terms of social relationships (Strauss 1977), and the Utku explain actions in terms of the desires of others instead of their own (Briggs 1970). Furthermore, there are several cultures for which the minds of others are considered unknown and unknowable. In such cultures there is little talk of mental states, even of one's own. ${ }^{5}$ In one such case (the Chewong), behavior is explained by explicit and elaborate rules governing social life (which may reduce need for the explanation or prediction via mental states; Lillard 1998).

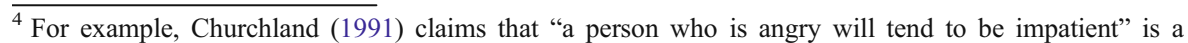
common homily that figures into causal/explanatory laws. Lillard (1998, p.16) supplies several examples of cultures in which anger in particular, or emotions more generally, are denied any causal power. To the extent that FP has laws, they are not universal laws that every culture recognizes.

${ }^{5}$ Such cultures are not a counter-example to claim that beliefs and desires are universal posits for understanding mental life. For these cultures do not have a radically different ontology for what occurs in the mind, rather they have a taboo against discussing the subject.
} 
Due to the enormous variation in the types of explanations offered by different cultures, it seems unlikely that any one (in particular ours) has some special access to the way in which the mind really works. Thus, the common sense principles that organize our understanding are unlikely to be preserved. However, beliefs and desires, as ontological entities, appear to have universal counterparts in every system and the ability to employ them seems to follow a universal course of development: so long as there is no organic impairment and so long as there is sufficient exposure, a ToM develops. ${ }^{6}$ This development is not governed by general learning strategies, but by content-specific brain regions. ${ }^{7}$ While universality is not proof that every possible alternative ontology must include this core, it is strong evidence that we are biologically determined to differentiate a "mental world" and to understand it in these terms.

\section{Why Does FP Succeed?}

Churchland notes that there are areas in which our folk psychological understanding fails: dreaming, the explanation of consciousness, mental disorders and so on. Further, he predicts that any empirical endeavor based on propositional attitudes is doomed. This position leads to a major challenge for Churchland. It raises the question of why FP works so well if it is radically false. Restrictive materialism has a ready answer.

Churchland frequently points out that folk psychology shares the same status as other folk theories. For example, humans make assumptions about the behavior of moving objects akin to the Aristotelian impetus theory (McCloskey 1983). Our naïve set of intuitions gets us around the world without falling off cliffs or getting hit by hurled objects, but when the requirements for accuracy and prediction become scientifically rigorous, such folk theories collapse. Whatever notion the folk hold is irrelevant to the scientific account of physics; if humans are disposed to act as if bodies have an impetus, so much the worse for humans. It is the business of physics to account for the movement of bodies, not how people think bodies move. But the same cannot be said for psychology; to account for how people think is exactly what psychology is in the business of. A complete psychology will include the folk theories people use to guide their behavior. It can be put like this: if people act as if objects have an impetus, then "impetus" will be a perfectly legitimate theoretical entity in psychology regardless of what physics finds. So too for beliefs and desires.

Consider a social psychologist explaining the behavior of a group of villagers who subscribe to the Witch Theory of natural disasters. The psychologist's employment of the concept "witch" will explain why the villagers occasionally torture and burn eccentric women. It matters little whether the psychologist believes in witches. If the task is to explain the actions of the group, and the term "witch" organizes a significant amount of otherwise unconnected behavior, then "witch"

\footnotetext{
${ }^{6}$ One of the cultures studied in Callaghan et al. (2005) is listed by Lillard (1998) as a culture that abstains from mental state attribution. While Samoan children lagged behind in their development of ToM, the children were equivalent to other cultures by age five.

${ }^{7}$ For supporting neurological evidence see Saxe and Kanwisher (2003).
} 
earns its ontological keep in the psychological account of the group's behavior. To the extent that the folk organize their behavior as if beliefs and desires exist, such terms will find a comfortable home in psychological accounts of behavior that is influenced by interpersonal or intrapersonal understanding.

I imagine that to some, such a shadowy existence would not license the ontological status of beliefs and desires. It would certainly not meet either of Fodor's (1985) requirements. Yet, in light of the argument of the previous section, only the principles of FP would be like the Witch Theory - knowing these principles would assist psychologists only in so far that they studied a culture that subscribed to it. Alternatively, beliefs and desires would be a stable fixture in theorizing. Further, it is a unique feature of psychology that requires the inclusion of folk psychology in the mature scientific theory. Psychology not only must explain how we think; it must also explain how we think we think. If FP is radically false, then how we actually think will differ radically from our untutored self-understanding, but both clearly fall into the domain of psychology. Thus: (1) to the extent that psychological phenomena depend on parsing the mental world; (2) to the extent to which such parsing is invariably in terms of beliefs and desires; and (3) to the extent to which this parsing influences behavior; I conclude that (4) beliefs and desires will invariably earn their keep the same as any other scientific term.

Accordingly, restrictive materialism counters the extreme position taken by EM by recognizing that the way in which we understand ourselves, even if radically false as a description of the actual workings of some of the brain, in turn influences our actions. There need not be witches, to have behavior that is organized by the concept. Similarly, restrictive materialism avoids the extreme position taken by a strict realist because it acknowledges that we are continually surprised to what extent we are strangers to ourselves. Restrictive materialism does not suggest that all of the story will be told with familiar terms. Not all, but some.

Yet it is more than just predictive accuracy which I claim grounds the ontological status of beliefs and desires. ${ }^{8}$ To see this, contrast restrictive materialism with Dennett's "intentional stance". For Dennett, all it means to say that an organism has beliefs and desires is that its behavior can be predicted by using the intentional stance (1987, p.252). So if we can predict the behavior of frogs with the intentional stance then ipso facto frogs have beliefs and desires. ${ }^{9}$ Here I reiterate Churchland's (1981) reminder that the intentional stance has historically been applied far more broadly than today (e.g. animism). Like him, I see this as an over-extension of FP, as much for frogs as for rivers.

If applying a western FP cross-culturally failed miserably to predict a foreigner's behavior, on instrumental criteria we would have to conclude that they are not, in Dennett's sense, true believers. In contrast, I have argued that organizing the world into beliefs and desires are physical processes in the brain. The ubiquity of this framework in radically different cultures speaks to the possibility that such a

\footnotetext{
${ }^{8}$ Such a position might be thought of as restrictive instrumentalism.

${ }^{9}$ Dennett (1991, p.143) draws a distinction between beliefs and opinions, where the former are perceptual states and the latter are linguistically infected. In his terminology I am mainly discussing opinions, but I think it is also the case that FP relies on what he terms opinions and so I maintain the disagreement is more than semantics.
} 
framework may be hardwired, though the principals may not be. The only people known to lack such a framework either are neurally atypical, such as people with an autism spectrum disorder, or lack sufficient exposure to foster normal development. Further, should it turn out that these processes are corrigible, I would agree with Churchland concerning their eventual elimination.

Perhaps it will be objected that if beliefs only exist because of the way the brain organizes intrapersonal or social content, then beliefs do not really exist. Indeed it would probably be more accurate to think of the acquisition of FP as enculturation than as theory development. ${ }^{10}$ For people with these intuitions, the matter remains in the air, but there is at least some evidence that both conscious desires and "unconscious desires" evoked by priming exhibit similar neural activation (Gardner, Bargh, Shellman, \& Bessenoff 1999, as cited in Bargh and Chartland 1999). It may turn out that beliefs and desires are simply different ways of harnessing phylogenetically older neural structure and in fact are the causes of behavior generally. In this case we might say they really do exist, but such a claim is far from substantiated.

Regardless, the empirical work being conducted in psychology largely assumes that beliefs and desires are adequate for some level of study. As for Churchland's concern regarding the incongruence of propositional attitudes with the rest of science, it should be noted that, not only in psychology, but in political science, sociology, and economics, beliefs and desires find an ontological home. ${ }^{11}$ Given that the introduction of ontology can proceed from higher levels of analysis (e.g. 'the atom' from chemistry to physics), the fact that there is no current account of how beliefs and desires emerge from neurochemistry should not impugn their status, so long as they are successful at some level of description.

Currently success abounds. The use of such a framework serves as a foundation for productive research programs in evolutionary psychology (Bogdan 2000); social psychology (Malle et al. 2001; Trabasso and Stein 1994); moral psychology (Haidt 2001); and most unfortunate for Churchlands case, neuroscience (Baron-Cohen et al. 1999). Contra Churchland, empirical research using beliefs and desires does not appear to be in stagnation.

Current research suggests that when used by the folk, beliefs and desires are not theoretical terms; they are the basic framework by which the brain organizes human behavior. While some may wish to withhold granting ontological status to beliefs and desires until they are certified by a mature neuroscience, such a day remains in the distant future. Yet with each empirical success of the common sense ontology in scientific psychology, the threat that naturalizing the mind will expose a radical failure is attenuated. Presently, research in many areas of psychology use these terms freely and productively. I can think of no better test of their ontological legitimacy than this.

\footnotetext{
$\overline{{ }^{10} \mathrm{I} \text { have used ToM because as }}$ it is in keeping with the literature on the topic. While some ToM researchers already agree that such abilities do not occur at the conscious level, even initially, they still maintain that beliefs and desires are theoretical terms. The universality of beliefs and desires would speak against conceiving of them as "theoretical" in any meaningful sense, regardless of whether ToM is a personal or subpersonal affair.

${ }^{11}$ Perhaps these are not sciences?
} 
Open Access This article is distributed under the terms of the Creative Commons Attribution Noncommercial License which permits any noncommercial use, distribution, and reproduction in any medium, provided the original author(s) and source are credited.

\section{References}

Avis, J., \& Harris, P. L. (1991). Belief-desire reasoning among Baka children: evidence for a universal conception of mind. Child Development, 62, 460-467.

Baron-Cohen, S. (1991). The Theory of Mind deficit in autism: How specific is it? British Journal of Developmental Psychology, 9, 301-314.

Baron-Cohen, S. (1995). Mindblindness: an essay on autism and theory of mind. Cambridge: MIT/ Bradford Books.

Baron-Cohen, S., Leslie, A., \& Frith, U. (1985). Does the autistic child have a Theory of Mind? Cognition, 21, 37-46.

Baron-Cohen, S., Leslie, A., \& Frith, U. (1986). Mechanical behavioral and intentional understanding of picture stories in autistic children. British Journal of Developmental Psychology, 4, 113-125.

Baron-Cohen, S., Ring, H., Wheelwright, S., Bullmore, E., Brammer, M., Simmons, A., et al. (1999). Social intelligence in the normal and autistic brain: an fMRI study. European Journal of Neuroscience, 11, 1891-1898.

Baron-Cohen, S., Tager-Flusberg, A., \& Cohen, D. (2000). Understanding other minds: Perspectives from developmental cognitive neuroscience. New York: Oxford University Press.

Bargh, J. A., \& Chartland, T. L. (1999). The unbearable automaticity of being. American Psychologist, 54, $462-479$.

Bogdan, R. J. (2000). Minding minds: Evolving a reflexive mind by interpreting others. Cambridge: MIT.

Briggs, J. (1970). Never in anger: A portrait of an Eskimo family. Cambridge: Harvard University Press.

Callaghan, T., Rochat, P., Lillard, A., Claux, M., Odden, H., Itakura, S., et al. (2005). Synchrony in the onset of mental-state reasoning: evidence from five cultures. Psychological Science, 16, 378-384.

Churchland, P. M. (1979). Scientific realism and the plasticity of mind. Cambridge: Cambridge University Press.

Churchland, P. M. (1981). Eliminative materialism and the propositional attitudes. Journal of Philosophy, 78, 67-90.

Churchland, P. M. (1991). Folk psychology and the explanation of human behavior. In J. Greenwood (Ed.), The future of folk psychology: Intentionality and cognitive science. Cambridge: Cambridge University Press.

Dennett, D. (1987). The intentional stance. Cambridge: MIT.

Dennett, D. (1991). Two contrasts: Folk craft versus folk science, and belief versus opinions. In J. Greenwood (Ed.), The future of folk psychology: Intentionality and cognitive science. Cambridge: Cambridge University Press.

Doherty, M. (2008). Theory of mind: How children understand others' thoughts and feelings. New York: Psychology.

Fodor, J. (1985). Fodor's guide to mental representation: the intelligent auntie's vade-mecum. Mind, 94, 55-97.

Fodor, J. (1987). Psychosemantics. Cambridge: MIT.

Haidt, J. (2001). The emotional dog and its rational tail: a social intuitionist approach to moral judgment. Psychological Review, 108, 814-834.

Happe, F. (1995). The role of age and verbal ability in the ToM performance of subjects with autism. Child Development, 66, 843-855.

Hardman, C. (1981). The psychology of conformity and self-expression among the Lohorung Rai of East Nepal. In P. Heelas \& A. Lock (Eds.), Indigenous psychologies (pp. 161-182). New York: Academic.

Karmiloff-Smith, A., Klima, E., Bellugi, U., Grant, J., \& Baron-Cohen, S. (1995). Is there a social module? Language, face processing and theory of mind in subjects with Williams syndrome. Journal of Cognitive Neuroscience, 7, 196-208.

Leekam, S. R., \& Perner, J. (1991). Do autistic children have a metarepresentational deficit? Cognition, 40, 203-218.

Leslie, A., \& Thaiss, L. (1992). Domain specificity and conceptual development: neuropsychological evidence from autism. Cognition, 43, 225-251.

Lillard, A. (1998). Ethnopsychologies: cultural variations in theories of mind. Psychological Bulletin, 123, 3-32. 
Malle, B. F., Moses, L. J., \& Baldwin, D. A. (2001). Intentions and intentionality: Foundations of social cognition. Cambridge: MIT.

McCloskey, M. (1983). Intuitive physics. Scientific American, 248, 122-130.

Miller, J. G. (1984). Culture and the development of everyday social explanation. Journal of Personality and Social Psychology, 46, 961-978.

Perner, J., Frith, U., Leslie, A., \& Leekam, S. (1989). Exploration of the autistic child's Theory of Mind: knowledge, belief, and communication. Child Development, 60, 689-700.

Peterson, C., \& Siegal, M. (2000). Insights into Theory of Mind from deafness and autism. Mind \& Language, 15, 123-145.

Saxe, R., \& Kanwisher, N. (2003). People thinking about thinking people-fMRI studies of Theory of Mind. Neuroimage, 19, 1835-1842.

Straus, A. (1977). Northern Cheyenne ethnopsychology. Ethos, 5, 326-352.

Tager-Flusberg, H., Boshart, J., \& Baron-Cohen, S. (1998). Reading the windows to the soul: evidence of domain-specific sparing in Williams syndrome. Journal of Cognitive Neuroscience, 10, 631-639.

Trabasso, T., \& Stein, N. L. (1994). Using goal-plan knowledge to merge the past with the present and the future in narrating events on line. In M. M. Haith \& J. B. Benson (Eds.), The development of future oriented processes: The John D. and Catherine T. MacArthur Foundation series on mental health and development (pp. 323-349). Chicago: University of Chicago Press.

Vaccari, C., \& Marschark, M. (1997). Communication between parents and deaf children: Implications for social-emotional development. Journal of Child Psychology and Psychiatry, 38, 793-801.

Vinden, P. (1999). Children's understanding of mind and emotion: a multi-culture study. Cognition and Emotion, 13, 19-48.

Wierzbicka, A. (1992). Semantics, culture, and cognition. Oxford: Oxford University Press.

Zahavi, D., \& Parnas, J. (2003). Conceptual issues in the study of infantile autism: Why cognitive science needs phenomenology. Journal of Consciousness Studies, 10(9), 53-71.

Zalla, T., Labruyere, N., \& Georgieff, N. (2006). Goal-directed action representation in autism. Journal of Autism and Developmental Disorders, 36(4), 527-540. 